\title{
Review
}

\section{Diabetic control and microvascular complications: the near-normoglycaemic experience}

\author{
K. F. Hanssen ${ }^{1,4}$, K. Dahl-Jørgensen ${ }^{2-4}$, T. Lauritzen ${ }^{6}$, B. Feldt-Rasmussen ${ }^{6}$, O. Brinchmann-Hansen ${ }^{5}$ and T. Deckert ${ }^{6}$ \\ ${ }^{1}$ Diabetes/Endocrine Section, Department of Medicine B, Departments of ${ }^{2}$ Pediatrics and ${ }^{3}$ Clinical Chemistry and ${ }^{4}$ Hormone Laboratory, \\ Aker University Hospital, and ${ }^{5}$ Eye Department, Ulleval University Hospital, Oslo, Norway; ${ }^{6}$ Steno Memorial Hospital, Gentofte, Denmark
}

The hypothesis that microvascular complications of diabetes are in part due to the lack of good blood glucose control was suggested soon after the introduction of insulin. It was not until recently, with the introduction of home blood glucose monitoring, glycosylated haemoglobin and better treatment with insulin pumps or multiple injections, that this hypothesis could be rigorously tested.

When Tchobroutsky [1] wrote his brilliant review on the topic in 1978, none of these techniques was in general use. Thus, the purpose of this review is to discuss the research carried out in this field since 1978, to pinpoint the difficulties in the design of such studies, and to draw some conclusions regarding the status of this issue in 1986. We will mostly concentrate on human studies, and we will consider only microangiopathy in Type 1 (insulin-dependent) diabetes mellitus.

\section{The association between long-term control and diabetic retinopathy}

Doft et al. [2] followed adolescents (aged 14-17.5 years) with diabetes of at least 8 years' duration for a mean period of 3 years; glycosylated haemoglobin was measured an average of 8 times prior to fluorescein angiography. There was a highly significant correlation between degree of metabolic control as measured by glycosylated haemoglobin and presence of early retinopathy as defined by angiography. The strength of this study is the close matching for chronological age and duration of diabetes in the groups with and without retinopathy. Weber et al. [3] showed similar results. Nine hundred and ninety-six Type 1 diabetic patients with age at diagnosis less than 30 years were included in the large Wisconsin epidemiologic study of diabetic retinopathy [4]. Masked grading of stereoscopic colour fundus photographs and single measurements of glycosylated haemoglobin were performed. In Type 1 patients with less than 10 years' duration, the group without retinopathy had lower glycosylated haemoglobin values than the group with retinopathy. Furthermore, the group with only microaneurisms after
10 years' duration had significantly lower glycosylated haemoglobin values than the group with the same severity after less than 10 years of diabetes. These observations suggest that the development of early retinopathy may have to do with the integral of glycosylated haemoglobin over the duration of diabetes.

However, it is necessary to point out that in both the Pittsburgh and Wisconsin studies the difference in glycosylated haemoglobin between patients with and those without retinopathy with the same duration of the disease is on average only about $1 \%$, indicating that many diabetic patients with poor metabolic control over the period studied did not develop retinopathy. In the long run, about $95 \%$ of diabetic patients will develop some retinopathy [4]. Also, in the above studies, no difference was shown in glycosylated haemoglobin between those with simplex and proliferative retinopathy, in contrast to a recent study [5]. In the Pittsburgh study [2], no correlation between isolated random blood glucose and retinopathy was shown, indicating that single blood glucose levels are not representative of blood glucose control.

The Joslin clinic [6] compared 111 patients with long-standing Type 1 diabetes who had proliferative retinopathy with 81 patients with similar duration (on average 26 years) who did not have proliferative changes. Those with proliferative changes had higher blood glucose levels on routine clinic visits. A multi-factorial model for the development of proliferative diabetic retinopathy was suggested.

Pirart [7], in his large prospective study, showed a correlation between the blood glucose control measured by blood and urinary glucose and the development of retinopathy.

\section{The association between long-term control and diabetic kidney disease}

The earliest changes firmly associated with the later development of diabetic nephropathy is increased excretion of albumin in urine. Three studies have shown that diabetic patients who have persistently elevated levels 
of excretion of albumin in urine (between $30-300 \mathrm{mg}$ / $24 \mathrm{~h}$ ) are at high risk of clinical diabetic nephropathy over the next 10-15 years [8-10]. Incipient diabetic nephropathy has been defined as two out of three urinary samples having elevated albumin excretion [10]. The relationship between the development of incipient nephropathy and glucose control has not been studied in detail. In a cross-sectional study, two groups of Type 1 diabetic patients with microalbuminuria were compared to a normoalbuminuric group. Both the high and low microalbuminuric group had higher glycosylated haemoglobin values and higher mean blood glucose levels when compared to the closely matched normoalbuminuric group [11]. Overall, a positive correlation between glycosylated haemoglobin levels and urinary albumin excretion rate was found. Multiple regression analysis showed that glycosylated haemoglobin levels and arterial blood pressure levels were independently correlated with albumin excretion rates. Deckert et al. [12] did not find any difference between the blood glucose control whether looking retrospectively or at a cross-sectional study between patients developing and those not developing diabetic nephropathy; however, glycosylated haemoglobin values were not available to assess earlier diabetic control.

The question of the relationship between development of persistent microalbuminuria and blood glucose control is a crucial one for several reasons. About $40 \%$ of Type 1 diabetic patients will develop diabetic nephropathy and will die from the disease if not dialysed or transplanted [13]. Furthermore, proteinuria in Type 1 diabetes is an indicator not only of subsequent renal death but also of early cardiovascular death, suggesting that macrovascular disease is more progressive in patients with persistent proteinuria [14].

Hasslacher et al. [15] showed that median postprandial glucose concentrations during the first 6 years of observation were significantly higher in patients who subsequently developed persistent proteinuria than those who did not. Furthermore, among the diabetic patients who developed nephropathy, a negative correlation was found between the median blood glucose levels and the time interval between diagnosis of diabetes and onset of persistent proteinuria.

\section{Influence of near normoglycaemia on retinopathy (near normoglycaemic re-entry)}

Keen [16] has recently coined the term "normoglycaemic re-entry". Several non-controlled, non-randomized studies have looked at the influence of near normoglycaemia on the progression of diabetic retinopathy. Apart from the few early enthusiastic case reports [17, 18], these short-term studies did not show any improvement in diabetic retinopathy. Some of them showed a worsening. In the study of 25 eyes with background retinopathy 11 worsened, including two eyes that develop- ed proliferative changes [19]. Four of 15 eyes with proliferative changes progressed, and no eye improved. This was a depressing result and, although there was no control group, the results were not encouraging. Other investigators have reported similar results $[20,21]$. Van Ballagooie et al. [22] showed a dramatic worsening in some patients. He studied 19 patients with Type 1 diabetes for 1 year. They were badly controlled beforehand and had a $50 \%$ reduction in mean blood glucose following continuous subcutaneous insulin infusion (CSII). Four patients with moderate to severe background retinopathy showed a rapid and severe progression of the fundal abnormalities, with development of florid proliferative diabetic retinopathy three to six months after starting CSII.

In another study, 33 Type 1 diabetic patients freely chose either CSII or conventional treatment and were followed for an average of 30 months. However, the degree of retinopathy was different in the two groups at the start of the study. A marginally better outcome for retinopathy was shown for the CSII group [23].

As Barbosa [24] clearly pointed out, to study the development and progression of diabetic microangiopathy, randomized trials with well-characterized Type 1 diabetic patients and good quantification of end-points for retinopathy and nephropathy are necessary. A few such studies have been published [25-35]. It is important to stratify the diabetics with respect to clinical variables at entry, i. e., to the different treatment groups. Only two of the studies did that [31, 34]. All studies achieved significantly different glycosylated haemoglobin levels between the control group and the experimental group. The near-normoglycaemia group was achieved with CSII in all studies; in the Oslo study an additional multiple injection group was included. The Aarhus group [33] had diabetic patients with little retinopathy and few with microalbuminuria. One year's results showed no change in these parameters. The Steno study was planned to study the influence of near normoglycaemia on the progression of established retinopathy. The diabetic patients had a mean duration of 19 years and established simplex retinopathy [25]. The degree of retinopathy were assessed by fundus photography and fluorescein angiography at $0,6,12$ and 24 months. A ranked classification of the colour fundus photographs and fluorescein angiograms were made according to the worst eye of each patient (Table 1). At 1 year, deterioration of retinopathy was more frequent in the CSII group than in the conventionally treated group, but the difference was not significant. At 2 years, improvement of retinopathy was more frequent among CSII than among unchanged conventional patients, although the difference was at most marginally significant. Four patients in the CSII group had proliferative retinopathy after 2 years compared to five patients in the unchanged conventional group. The patients who developed proliferative retinopathy had a significantly worse baseline retinal morphology ranking, macular re- 
Table 1. Blind ranking of fluorescein angiography with changes during 2 years (number of patients)

\begin{tabular}{llllllll}
\hline & \multicolumn{3}{l}{ CSII } & & \multicolumn{3}{l}{ Conventional } \\
\cline { 2 - 4 } \cline { 7 - 8 } \cline { 6 - 8 } & Oslo & Steno & Combined & & Oslo & Steno & Combined \\
\hline Improved & 1 & 7 & 8 & & 1 & 2 & 3 \\
Unchanged & 8 & 2 & 10 & 6 & 2 & 3 \\
Deteriorated & 4 & 6 & 10 & & 8 & 10 & $18^{\mathrm{a}}$ \\
\hline
\end{tabular}

${ }^{a}$ Deterioration significantly less $(2 \mathrm{p}<0.03)$ in the combined Oslo/ Steno continuous subcutaneous insulin infusion treatment (CSII) when compared to conventional treatment.

covery time and oscillatory potentials when compared to those who did not develop retinopathy. The most common reason for deterioration of fundus photographs was appearance of further cotton wool spots ("exudates"), haemorrhages and "red spots", and on fluorescein angiograms, appearance of further microaneurisms, haemorrhages and capillary-free areas.

The Kroc collaborative study [28] randomized 65 Type 1 diabetic patients with a mean duration of diabetes of 17 years and slightly less retinopathy at inclusion than the patients in the Steno study. The study's results were based on eight standard field colour photos of each eye at 0 and 8 months. The retinopathy was graded according to a grading scale developed by the Fundus Photograph Reading Center at the University of Wisconsin. The results were very similar to the 1-year result of the Steno study. The mean retinopathy level was recorded as improved in only four patients (three in the conventional group and one in the CSII group). Deterioration assessed by the mean retinopathy level was greater in the CSII group (15 of 32 patients) than in the conventionally treated group ( 9 of 33 patients). Progression was most commonly accounted for by the appearance of cotton wool spots or intra-retinal microvascular abnormalities or both. A multivariate classification analysis of the progression of retinopathy indicated lower plasma glucose as the best single predictor of worsening of retinopathy [29]. The Kroc study was designed as a feasibility trial for 8 months, but half of the patients continued in their treatment group for an additional 16 months. The 2-year data showed the opposite results. Compared to the start of the study, the patients in the CSII group had slightly less retinopathy than the conventionally treated group [30]. However, there were many dropouts from the first to the second year. Nevertheless, as in the Steno study, the 2-year results indicate that the initial worsening of retinopathy is a transient one if the retinopathy is not too advanced when starting intensified treatment.

The Oslo study included 45 Type 1 diabetic patients of more than 7 years' duration, regardless of whether they had simplex retinopathy [31]; $25 \%$ did not have visible retinopathy on fluorescein angiograms at entry. The Type 1 diabetic patients were subrandomized at entry according to age, duration of disease, sex, glycosylated haemoglobin, and degree of retinopathy into three treatment groups: 15 received conventional treatment (two times a day of mixed regular and NPH insulin); 15 received multiple injection therapy (regular insulin before each meal (4-5 times daily) and NPH at bedtime), and 15 treated themselves with CSII. Both colour fundus photographs and fluorescein angiography were performed at times 2, 0, 3, 6, 12 and 24 months. A continuous progression of retinopathy was shown in the conventional group. In the CSII group, a significant deterioration was observed during the first 3 months. In the multiple injection group, no significant changes were detected. One patient developed transient proliferative retinopathy in both eyes after three months of CSII [21]. CSII treatment was continued, and within 3 months almost all retinal changes had regressed without laser treatment.

In the study as a whole, 15 patients were identified by indirect ophthalmoscopy and binocular split lamp biomicroscopy as developing cotton wool spots after 3-6 months of treatment. No patient in the conventionally treated group developed cotton wool spots. Patients who developed cotton wool spots differed in their diabetic control from those treated by CSII and multiple injections who did not develop these changes. Patients who developed cotton wool spots were characterized by a larger decrement in mean blood glucose values and glycosylated haemoglobin values, more frequent episodes of hypoglycaemia, a longer duration of diabetes, and more severe retinopathy at the start of intensified treatment.

As in the Steno and Kroc studies, the two-year results regarding retinopathy were quite different [32]. By evaluating microaneurysm (red spot) count, which previously had been found to be a reliable marker of early retinopathy [36], microaneurysms increased significantly at 2 years in the conventionally treated group $(p<0.01)$. In the CSII group, no significant difference in microaneurysm count was detectable between 0 and 2 years. In the multiple injection group as well, no significant progression between 0 and 2 years was found. These results demonstrate that intensified treatment, whether it is by CSII or multiple injections, can retard (or prevent) the progression of early retinopathy over a 2-year period. Although evaluation of the total retinopathy from the angiograms did not indicate any significant difference between the three different treatment groups, when the patients treated with CSII and conventional treatment in the Steno and Oslo studies were combined, a highly significant difference between the deterioration in retinopathy in CSII and conventional treatment is evident (Table 1).

It should be pointed out that there are many methodological considerations which make it questionable to combine these studies. The Steno study had more advanced retinopathy at the start, and the methods for assessing progression were slightly different in both studies. However, the combined 2-year results of the Steno/Oslo study clearly indicate that intensified insu- 
lin treatment during 2 years retards or prevents the progression of diabetic retinopathy.

The problems in assessing the influence of near-normoglycaemia on the development and progression of diabetic retinopathy is partly due to the totally unexpected deterioration in diabetic retinopathy found by many investigators shortly after initiating intensified insulin treatment $[20,21,25,28,31]$. Thus, by studying the diabetic patients for just 1 year, one might get the impression that indeed intensified insulin treatment is harmful to the retina. However, it is not surprising that it should take longer than 1 year to stop or reverse a lesion like diabetic retinopathy which has been evolving for about $10-15$ years before becoming clinically significant.

It should be pointed out, however, that it is not necessary to treat patients with insulin pumps or multiple injections to experience an initial deterioration in retinopathy [37]. Daneman et al. [38] observed that, by giving badly treated children (Mauriac syndrome) insulin only twice daily, a similar phenomenon of worsened diabetic retinopathy was evident. Furthermore, case reports on the development of proliferative retinopathy during intensified two-injection insulin therapy in Type 1 diabetic patients of only 5 years' duration (Haakens, personal communication) and after starting diet treatment in Type 2 (non-insulin-dependent) diabetes mellitus (Bjørnstad, personal communication) showed that it is not the intensified insulin treatment itself that is important but the relatively abrupt lowering of blood glucose. Whether the number of hypoglycaemic episodes or the lowering of mean glycaemia as such is important is unclear. However, we favor the view that it is the lowering of blood glucose or factors associated with this that represent the major causal factor. Whether the rate of fall of blood glucose is important is speculative. To discover the transient worsening of retinopathy it is important to do an ophthalmological examination during the first 3-6 months after a considerable fall in mean blood glucose levels. Whether it is necessary to perform this examination as a routine procedure is not clear. However, it is evident that diabetic retinopathy may change relatively rapidly, more so than believed until recently. Not much is known about the mechanism for this deterioration in retinopathy, but hypoxia and ischaemia seem to be common denominators in both background and preproliferative retinopathy. Although speculative, a pathophysiological model may be adapted to explain our findings [39]. The rate of oxygen consumption is higher and the oxygen release capacity is reduced in diabetic patients compared to normal subjects. The relative hypoxia may worsen further because of the reduced oxygen consumption of the retina found in hyperglycaemia. When hyperglycaemia also impairs retinal oxygen autoregulation, a rapid decrease in blood glucose deprives the retina of oxygen and nutritive elements. The increased retinal blood flow may also be substantially reduced after a rapid normalization of blood glucose, and relative hypoperfusion may result. Brinchmann-Hansen et al. [40] have recently shown that a widened diameter of both veins and arteries, signifying vasodilation and increased blood flow, predict the development of cotton wool spots upon intensifying insulin treatment.

\section{The influence of near normoglycaemic re-entry on diabetic nephropathy}

Whether near normoglycaemia can influence the development and progression of early diabetic nephropathy has been studied extensively during the last few years $[41,44-47]$. Earlier studies have shown that exercise-induced albumin excretion is reversible with CSII treatment [42]. However, the predictive value of exercise-induced albuminuria for diabetic kidney disease has recently been questioned [43], and later studies have relied on baseline excretion of albumin during overnight collection, 4-h timed or 24-h collections. When clinical diabetic nephropathy has developed (excretion of more than $500 \mathrm{mg}$ of urinary protein $/ 24 \mathrm{~h}$ ), further progression of the disease is unaffected by improved control for 1-2 years [45]. In an uncontrolled study by Tamborlane et al. [41], near normoglycaemia did not influence the progression of diabetic nephropathy. It must be emphasized, however, that high blood glucose levels in themselves may lead to increased excretion of albumin in urine $[44,45]$. This is rapidly reversible after instituting fair blood glucose control.

In a group of diabetic patients with intermittent proteinuria (positive Albustix at no more than two consecutive occasions over a period of at least 1 year), Bending et al. [48] did not show any influence of near normoglycaemia over a period of 6 months. However, the albumin excretion rate proved to be widely different at baseline among different subjects, ranging from a normal $7 \mathrm{mg} / \mathrm{min}$ to $286 \mathrm{mg} / \mathrm{min}$, making a conclusion difficult.

\section{Influence of near normoglycaemia on incipient nephropathy}

Incipient nephropathy can be defined as at least two out of three sterile 24-h collections in the range of $30-300 \mathrm{mg} / 24 \mathrm{~h}(20-200 \mu \mathrm{g} / \mathrm{min})$.

The randomized studies investigating diabetic retinopathy have also studied certain aspects of incipient diabetic nephropathy. None of the studies showed an early worsening of albuminuria, as was shown for diabetic retinopathy when instituting near normoglycaemia. The Steno study included eight diabetic patients with incipient nephropathy. Over a 2-year period, five in the conventional group progressed to clinical proteinuria compared with only one in the CSII group [49]. In the Kroc study, 10 diabetic patients in each treat- 
ment group initially had supranormal albumin excretion $(>12 \mathrm{mg} / \mathrm{min})$. The patients with supranormal albuminuria who received CSII had a progressive decline in albumin excretion [28]. However, as there is a $40-50 \%$ variation in the excretion of urinary albumin from one day to another [50], relying on single urinary samples, as the Kroc study did, makes interpretation of the results uncertain [51].

In the Oslo study, mean urinary albumin excretion was only slightly elevated at the start of the study. Urine albumin decreased significantly after 3 to 4 years of CSII ( 26 to $16 \mathrm{mg} / \mathrm{h}, p<0.05$ ). Urine albumin remained unchanged during conventional treatment (21 vs $22 \mathrm{mg} / 24 \mathrm{~h}$ ) (unpublished observation).

In a new trial, a prospective randomized study looked specifically at the influence of near normoglycaemia on the progression of incipient diabetic nephropathy in 36 Type 1 diabetic patients with persistently elevated urinary albumin randomized to conventional treatment or CSII. At 1 year [34], kidney size was reduced, but no significant changes in glomerular filtration rate or urinary albumin were observed. However, at 2 years' observation, using a more sensitive technique for following urinary albumin excretion longitudinally in the individual patients (longitudinal regression lines), the progressive increase in urinary albumin excretion continued in the conventional treatment group and was arrested or even reversed in the CSII group $(2 p<0.03)$. Glomerular filtration rate was reduced significantly in the CSII treated group and unchanged in the CIT treated group [35]. Furthermore, after 2 years five patients in the conventionally treated group had developed clinical nephropathy (albuminuria $>300 \mathrm{mg} / 24 \mathrm{~h}$ ) versus none in the CSII group $(p<0.05)$. These are very encouraging results, but we do not know as yet whether the reduction in albuminuria in the CSII group in the long term will prevent renal insufficiency in these patients.

\section{Near normoglycaemia and diabetic neuropathy}

Diabetic neuropathy may be the most common diabetic complication. The relationship between changes in nerve conduction velocity and clinical diabetic neuropathy has been unclear. Recent studies both in man [52] and in the spontaneously diabetic BB rat $[53,54]$ suggest that reduction in nerve conduction velocity is indeed sensitive and reliable in the detection of diabetic neuropathy.

Gregersen [55] has shown as early as 1967 that, when poorly controlled diabetic patients were fairly well controlled, their motor nerve conduction velocity improved. Many investigators have described similar results $[56,57]$.

Moreover, positive correlations between nerve conduction velocities and blood glucose control have been found in numerous studies [57, 58]. Although recent studies have described improvement of nerve conduc- tion velocities in acute metabolic neuropathy during CSII [59, 61], few patients were included in these studies; only two studies included a control group [60, 62], and none had frequent initial nerve conduction velocity measurements to distinguish between acute metabolic and chronic neuropathy. Recently, in a small randomized trial [62] with six diabetic patients treated with CSII and six treated conventionally, no changes were shown regarding any parameter after four months (they studied 40 different parameters), but after 8 months a small but significant difference was shown for a few of these parameters. However, the authors are fully aware of the difficulties in their conclusions due to the short observation period and small number of diabetic patients studied. In the Oslo study [32], we investigated motor nerve conduction velocities in three nerves and sensory nerve conduction in two nerves, amplitude of sensory action potentials and vibration perception threshold. No significant changes in motor nerve conduction velocity were observed in any of the groups during the preperiod or the first year. However, after 2 years a significant improvement of motor nerve conduction velocity was observed in the CSII group in all nerves tested when compared to the conventional group, in which deterioration was found. The difference in motor nerve conduction velocity was up to $6 \mathrm{~m} / \mathrm{s}$ (n. ulnaris) when comparing CSII and conventional treatment.

It is important to note that all diabetic patients had motor nerve conduction velocities within the normal range and no clinical signs of diabetic neuropathy when intensified insulin treatment was started. Nevertheless, they increased their nerve conduction velocities substantially compared to the conventionally treated group. It is tempting to speculate that near normoglycaemia reverses the early phase of diabetic neuropathy as has been shown in the BB rat [53]. It thus appears that CSII treatment is highly effective, much more so than the marginal effect shown by aldose reductase inhibitors [63] in maintaining normal nerve conduction velocities. Autonomic neuropathy, as evidenced by beat to beat variation, deteriorated in the conventional group and did not change in the CSII group in the Steno Study [26].

\section{Concluding remarks}

We have summarized recent data from a series of studies carried out since 1978 whose results show that blood glucose levels are important for the development and progression of diabetic microangiopathy in humans. These studies have shown that 2 years of near normoglycaemia retard or arrest the progression of diabetic microangiopathy in the kidney, retina, autonomic and peripheral nerves. These are highly encouraging results. 


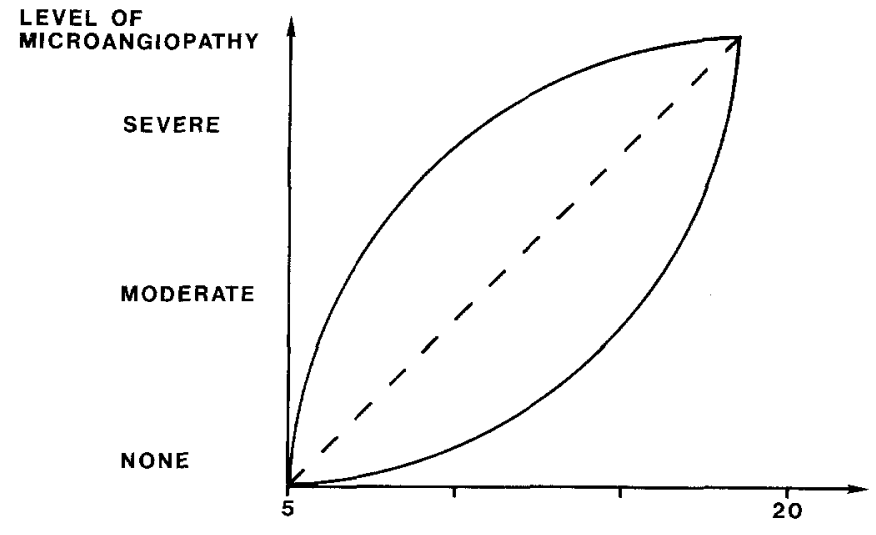

MEAN BLOOD GLUCOSE $(\mathrm{mmo} / /)$

Fig. 1. Hypothetical relationship between mean blood glucose levels and levels of diabetic microangiopathy

We think that the question to be addressed in the future is not in essence why but how to maintain good metabolic control. This is a formidable task and there are many difficulties ahead. One must ask if the blood glucose level needs to be totally normalized. It is obvious from the data that what we call "near normoglycaemia" is far from normal, with large oscillations; for the majority of even the intensively treated patients, glycosylated haemoglobin levels are still outside the normal range. It is important to realize that almost all the patients subsequently developed some retinopathy in the Wisconsin study [4], meaning that even the best regulation achieved in the past was unable to completely avoid diabetic retinopathy. The dose-response curve for the relationship between hyperglycaemia and diabetic microangiopathy is not known (Fig. 1). Furthermore, it is obvious that all microvascular complications are strongly correlated to the known duration of the disease as well as the glucose levels achieved. We might think of an integral of glycosylated haemoglobin levels over the years of disease as the crucial determinant.

The findings we have presented in this review do not of course rule out the possibility that additional factors may be important in the development and progression of diabetic angiopathy, among those an individual susceptibility to tissue damage by high blood glucose. To date those genetic factors which can be identified at present have not been shown to play a major role in the development of microangiopathy [64].

To develop strategies to help Type 1 diabetic patients cope with their disease and achieve as good blood glucose control as possible is a formidable task. Keystones are education [65] and motivation [66].

Recently available techniques of home blood glucose monitoring, glycosylated haemoglobin, insulin injection pens to facilitate multiple injection regimes, and insulin pumps all have their place in this effort. Near normoglycaemia can be achieved, but the problem of serious hypoglycaemia is very important and potentially dangerous [67].
The benefits of the best possible metabolic control for Type 1 diabetic patients are well documented and proven; the methods on how to achieve this goal remain a matter of further investigation and trial.

Acknowledgements. This review was written during a leave of tenure of one of the authors (KFH) at the Mayo Clinic, Rochester, Minn., USA. He would like to express his thanks to Dr. J.E. Gerich for excellent working conditions and to P. Voelker for superb editorial assistance. The referenced author's research has been supported by the Norwegian Council for Science and the Humanities; Norwegian Diabetes Association; Jahres Medical Foundation; Norwegian Council for Cardiovascular Diseases; University of Oslo; Nordisk Gentofte; Danish Medical Research Council; Danish Diabetes Association.

\section{References}

1. Tchobroutsky G (1978) Relation of diabetic control to development of microvascular complications. Diabetologia 15: 143-152

2. Doft BH, Kingsley LA, OrchardTF, Kuller L, Drash A, Becker D (1984) The association between long-term diabetic control and early retinopathy. Ophthalmology 91: 763-769

3. Weber B, Burger W, Hartmann R, Hövener G, Malchus R, Oberdisse U (1986) Risk factors for the development of retinopathy in children and adolescents with type 1 (insulin-dependent) diabetes mellitus. Diabetologia 29: 23-29

4. Klein R, Klein BEK, Moss SE, Cavid MD, DeMets DL (1984) The Wisconsin epidemiologic study of diabetic retinopathy. II. Prevalence and risk of diabetic retinopathy when age of diagnosis is less than 30 years. Arch Ophthalmol 102: 520-526

5. Sjølie AK (1985) Ocular complications in insulin treated diabetes mellitus. Acta Ophthalmol 63 (Suppl 172)

6. Rand LI, Krolewski AS, Aiello LM, Warran JH, Baker RS, Maki T (1985) Multiple factors in the prediction of risk of proliferative diabetic retinopathy. N Engl J Med 313: 1433-1438

7. Pirart F (1977) Diabete et complications degeneratives. Presentation d'une etude prospective portant sur 4400 cas observe entre 1947 et 1973. Diabete Metab 3:97-107, 173-182, 245-256

8. Parving H-H, Oxenbøll B, Svendsen PA, Christiansen JS, Andersen AR (1982) Early detection of patients at risk of developing diabetic nephropathy: a longitudinal study of urinary albumin excretion. Acta Endocrinol 100:550-555

9. VibertiGC, HillRD, JarrettRF, Argyropoulos A, MahmudU, Keen $\mathrm{H}$ (1982) Microalbuminuria as a predictor of clinical nephropathy in insulin-dependent diabetes mellitus. Lancet 1: 1430-1432

10. Mathiesen ER, Oxenbøll B, Johansen K, Svendsen PA, Deckert T (1984) Incipient nephropathy in Type 1 (insulin-dependent) diabetes mellitus. Diabetologia 26: 406-410

11. Wiseman M, Viberti GC, Mackintosh D, Jarrett RF, Keen H (1984) Glycemia, arterial pressure and microalbuminuria in Type 1 (insulin-dependent) diabetes mellitus. Diabetologia 26: 401-405

12. Deckert T, Poulsen JE (1981) Diabetic nephropathy: fault or destiny. Diabetologia 21: 178-183

13. Andersen AR, Christiansen JS, Andersen JK, Kreiner S, Deckert T (1983) Diabetic nephropathy in Type 1 (insulin-dependent) diabetes: An epidemiological study. Diabetologia 25: 496-501

14. Borch-Johnsen K, Andersen PK, Deckert T (1985) The effect of proteinuria on relative mortality in Type 1 (insulin-dependent) diabetes mellitus. Diabetologia 28: 590-596

15. Hasslacher C, Stech W, Wahl P, RitzE (1985) Blood pressure and metabolic control as risk factors for nephropathy in Type 1 (insulin-dependent) diabetes. Diabetologia 28: 6-11

16. Keen H (1984) Normoglycaemic re-entry and diabetic complications. Diabetic Med 1: 85-87

17. Irsigler K, Knitz H, Najemnik C, Freiger H (1979) Reversal of florid diabetic retinopathy. Lancet $2: 1068$ 
18. White MC, KohnerEM, Pickup FC, Keen H (1981) Reversal of diabetic retinopathy by continuous subcutaneous insulin infusion: a case report. Br J Ophthalmol 65: 307-314

19. Puklin JE, Tamborlane WV, Felig P, Genel M, Sherwin RS (1982) Influence of long-term insulin infusion pump treatment of type I diabetes on diabetic retinopathy. Ophthalmology 89:735-747

20. Lawson PM, Champion MC, Canny CLB, Kingsley R, White MC, Dupre J, Kohner EM (1982) Continuous subcutaneous insulin infusion does not prevent progression of proliferative and preproliferative retinopathy. Br J Ophthalmol 66: 762-766

21. Dahl-Jørgensen K, Hanssen KF, Brinchmann-Hansen O (1983) What happens to the retina as diabetic control is tightened? Lancet 1: 652

22. van Ballegooie E, Hooymans JMM, Timmerman Z, Reitsma WD, Sluiter WJ, Schweitzer NMJ, Doorenbos H (1984) Rapid deterioration of diabetic retinopathy during treatment with continuous subcutaneous insulin infusion. Diabetes Care 7: 236-242

23. Friberg TR, Rosenstock F, Sanborn G, Vagheti A, Raskin P (1985) The effect of long-term near normal glycemic control on mild diabetic retinopathy. Ophthalmology 92: 1051-1058

24. Barbosa J (1983) Diabetes: The science and the art, hyperglycemia complications. Arch Intern Med 143: 1118-1119

25. Lauritzen T, Frost-Larsen K, Larsen HW, DeckertT, The Steno Study Group (1983) Effect of 1 year of near-normal blood glucose levels on retinopathy in insulin-dependent diabetes. Lancet 1: $200-204$

26. Lauritzen T, Frost-Larsen K, Larsen H-W, Deckert T, and the Steno Study Group (1985) Two-year experience with continuous subcutaneous insulin infusion in relation to retinopathy and neuropathy. Diabetes 35 (Suppl 3): 74-79

27. Lauritzen T (1985) Pharmacokinetic and clinical aspects of intensified subcutaneous insulin therapy. Dan Med Bull 32,2: 104-118

28. Kroc Collaborative Study Group (1985) Blood glucose control and the evolution of diabetic retinopathy and albuminuria. $\mathrm{N}$ Engl J Med 311: 365-372

29. Testa MA, PuklinJE, Sherwin RS, Simonson DC (1985) Clinical predictors of retinopathy and its progression in patients with type I diabetes during CSII or conventional insulin treatment. Diabetes 34 (Suppl 3): 61-68

30. Kroc Study Group (1985) Effect of diabetic control on retinopathy. Follow-up report of the Kroc randomized clinical trial. Invest Ophthalmol Vis Sci 26 (Suppl 1): 85

31. Dahl-Jørgensen K, Brinchmann-Hansen O, Hanssen KF, Sandvik L, Aagenaes $\varnothing$, Aker Diabetes Group (1985) Rapid tightening of blood glucose control leads to transient deterioration in retinopathy in insulin-dependent diabetes mellitus - The Oslo Study. Br Med J 290: 811-815

32. Dahl-Jørgensen K, Brinchmann-Hansen O, Hanssen KF, Ganes T, Bjoro T, Sandvik L, Aagenæs Ø, Aker Diabetes Group (1986) Near-normoglycemia retards the progression of early diabetic retinopathy and neuropathy. Br Med J (in press)

33. Beck-Nielsen H, Richelsen B, Mogensen CE, Olsen T, Ehlers N, Nielsen CB, Charles P (1985) Effect of insulin pump treatment for one year on renal function and retinal morphology in patients with IDDM. Diabetes Care 8: 585-589

34. Feldt-Rasmussen B, Mathiesen ER, Hegedus L, Deckert T (1986) Kidney function during 12 months of strict metabolic control in insulin-dependent diabetic patients with incipient nephropathy. $\mathrm{N}$ Engl J Med 314: 665-670

35. Feldt-Rasmussen B, Mathiesen ER, Deckert T (1986) Effect on the progression of diabetic renal disease during 2 years of strict metabolic control in insulin-dependent diabetes. Diabetes 35:425 A

36. Baudoin C, Maneschi F, Quentil G, Soubrane G, Hayes T, Jones G, Cascas G, KohnerEM (1983) Quantitative evaluation of fluorescein angiograms: Microaneurism counts. Diabetes 32 (Suppl2): $8-13$

37. Harrad RA, PlumpAP, Rose GE, Morris RW, Sönksen PH (1984) Two year prospective study of improved control in diabetic patients with background retinopathy. Diabetologia 27: 285 A
38. Daneman D, Drash AL, Lobes LA, BeckerDF, Baker LM, Travis LB (1981) Progressive retinopathy with improved control in diabetic dwarfism (Mauriac's syndrome). Diabetes Care 4:360-365

39. Brinchmann-Hansen O, Dahl-Jørgensen K, Hanssen KF, Sandvik L, and Oslo Diabetes Study Group (1985) Effects of intensified insulin treatment on various lesions of diabetic retinopathy. Am J Ophthalmol 100: 644-653

40. Brinchmann-Hansen O, Dahl-Jørgensen K, Hanssen KF, Sandvik $L$. Diameter of retinal vessels and progression of diabetic retinopathy. Unpublished observation

41. Tamborlane WV, Puklin FE, Bergman M, VerdonkC, Rudolf MC, Felig P, Genel M, Sherwin R (1982) Long-term improvement of metabolic control with the insulin pump does not reverse diabetic microangiopathy. Diabetes Care 5 [Suppl 1]: 58-64

42. Koivisto VA, Huttunen N-P, Vierikko P (1981) Continuous subcutaneous insulin infusion corrects exercise-induced albuminuria in juvenile diabetes. Br Med J 282: 778-779

43. Feldt-Rasmussen B, Baker L, Deckert T (1985) Exercise as a provocative test in early renal disease in Type 1 (insulin-dependent) diabetes: Albuminuric, systemic and renal hemodynamic responses. Diabetologia 28: 389-396

44. Parving H-H, Noer I, Deckert T, Errin P-E, Nielsen SL, Lyngsøe J, Mogensen CE, Rorth M, Svendsen PA, Trap-Jensen J, Lassen NA (1976) The effect of metabolic regulation on microvasular permability to small and larbe molecules in short term juvenile diabetics. Diabetologia 12: 161-166

45. Viberti GC, Bilous RW, Mackintosh D, Bending JJ, Keen H (1983) Long-term correction of hyperglycaemia and progression of renal failure in insulin-dependent diabetes. Br Med J 286: 598-601

46. Viberti GC, Pickup FC, Jarrett RF, Keen H (1979) Effect of control of blood glucose on urinary excretion of albumin and $\mathrm{B}_{2}$-microglobulin in insulin-dependent diabetes. $N$ Engl J Med 300: $638-641$

47. Gavarella A, Vannini P, Flammini M, Bacci L, Forlani G, Borgnino (1985) Effect of long-term near-normoglycemia on the progression of nephropathy. Diabete Metab 77:3-8

48. Bending JJ, VibertiGC, Watkins PJ, Keen H (1986) Intermittent clinical proteinuria and renal function in diabetes: evolution and the effect of glycaemic control. Br Med J 292: 83-86

49. Deckert T, Lauritzen T, Parving H-H, Christiansen JS, The Steno Study Group (1984) Effect of two years of strict metabolic control on kidney function in long-term insulin-dependent diabetes. Diab Nephrop 3: 6-10

50. Feldt-Rasmussen B, Mathiesen ER (1984) Variability of urinary albumin excretion in incipient diabetic nephropathy. Diab Nephrop 3: 101-103

51. Feldt-Rasmussen B, Mogensen CE, Christiansen CK, Mathiesen ER, Deckert T (1984) Blood glucose control and diabetic microangiopathy. N Engl J Med 311: 1577-1528

52. Dyck PJ, Karnes JL, Daube J, O’Brien P, Service FJ (1985) Clinical and neuropathological criteria for the diagnosis and staging of diabetic polyneuropathy. Brain 708: 861-880

53. Sima AAF, BrismarT (1985) Reversible diabetic nerve dysfunction: Structural correlates to electrophysiological abnormalities. Ann Neurol 18: 21-29

54. Sima AAF, Lattimer SA, Yagihashi S, Greene DA (1986) Axo-glial dysjunction. A novel structural lesion that accounts for poorly reversible slowing of nerve conduction in the spontaneously diabetic bio-breeding rat. J Clin Invest 77: 474-484

55. Gregersen G (1967) Diabetic neuropathy: Influence of age, sex, metabolic control and duration of diabetes on motor nerve conduction velocity. Neurology (NY) 17: 972-980

56. Ward JD, Barnes CG, FisherDJ, Jessup JD, Baker RWR (1971) Improvement in nerve conduction following treatment in newly diagnosed diabetes. Lancet 1: 428-430

57. Graf RJ, Halter JB, Pfeifer MA, Harlan E, Brozovich BSE, Porte D (1981) Glycemic control and nerve conduction abnormalities in noninsulin dependent diabetic subjects. Ånn Intern Med 94: 307-311 
58. Boulton AJM, Worth RC, Drury J, HardistyCA, WolfE, Cudworth AG, Ward JD (1984) Genetic and metabolic studies in diabetic neuropathy. Diabetologia 26: 15-19

59. Boulton AJM, Drury J, Clark B, Ward JD (1982) Continuous subcutaneous insulin infusion in the management of painful diabetic neuropathy. Diabetes Care 5: 386-390

60. Pietri A, Ehle AL, Raskin P (1980) Changes in nerve conduction velocity after six weeks of glucoregulation with portable insulin infusion pumps. Diabetes 29:668-671

61. Gambardelia S, Napoli A, Spallone V, Verrastsro AM, Lazzan R, Geraldine C, Sideri G, ManzingerG (1983) Influence of glucoregulation with continuous subcutaneous insulin infusion on nerve conduction velocity and beat to beat variation in diabetes. $\mathbf{J}$ Endocrinol Invest 6: 363-369

62. Service FJ, Rizz RA, Daube JR, O’Brien PC, Dyck PJ (1985) Near normoglycemia improved nerve conduction and vibration sensation in diabetic neuropathy. Diabetologia 28: 722-727

63. Jaspan J, Maselli R, Herold K, Bartkus C (1983) Treatment of severe painful neuropathy with an aldose reductase inhibitor: Relief of pain and improved somatic and autonomic nerve function. Lancet 2: 758-762
64. Barbosa J (1984) Do genetic factors play a role in the pathogenesis of diabetic microangiopathy. Diabetologia 27: 487-492

65. Assal JP, Berger M, Gay N, CanivetJ (eds) (1983) Diabetes education: how to improve patient education, ICS No624. Excerpta Medica, Amsterdam

66. Tattersall RB, McCulloch DK, Aveline M (1985) Group therapy in the treatment of diabetes. Diabetes Care 8:180-188

67. Unger RH (1982) Meticulous control of diabetes: Benefits, risks and precautions. Diabetes 31: 479-483

68. Thorsteinsson B, Pramming S, Lauritzen T, BinderC (1986) Frequency of daytime biochemical hypoglycaemia in insulin-treated diabetic patients: relation to daily median blood glucose concentrations. Diabetic Med 3: 147-151

Dr. Kristian F. Hanssen

Chief, Diabetic Unit

Aker Sykehus

N-0514 Oslo 5

Norway 